\title{
Mutations in exon 8 of TP53 are associated with shorter survival in patients with advanced lung cancer
}

\author{
YUTAO LIU $^{1 *}$, FANG XU ${ }^{2 *}$, YUBO WANG $^{3}$, QINGCHEN WU $^{4}$, BUHAI WANG $^{5}$, \\ YANWEN YAO $^{6}$, YU ZHANG ${ }^{7}, \mathrm{HAN} \mathrm{HAN-ZHANG}^{8}, \mathrm{JUNYI} \mathrm{YE}^{8}, \mathrm{LU} \mathrm{ZHANG}^{8}$, \\ XINRU MAO ${ }^{8}$, ZHE ZHANG $^{8}$, JING LIU $^{8}$, LIANGJUN ZHU $^{9}$ and RENHUA GUO ${ }^{10}$
}

\begin{abstract}
${ }^{1}$ Department of Medical Oncology, National Cancer Center/National Clinical Research Center for Cancer/
Cancer Hospital, Chinese Academy of Medical Sciences and Peking Union Medical College, Beijing 100021;

${ }^{2}$ Department of Thoracic Medicine, Hunan Cancer Center and The Affiliated Cancer Hospital of Xiangya School of Medicine, Central South University, Changsha, Hunan 410006; ${ }^{3}$ Department of Respiratory Medicine, Daping Hospital, Third Military Medical University; ${ }^{4}$ Department of Cardiothoracic Surgery, The First Affiliated Hospital of Chongqing Medical University,

Chongqing 400042; ${ }^{5}$ Department of Medical Oncology, Subei People's Hospital of Jiangsu Province, Yangzhou, Jiangsu 225001; ${ }^{6}$ Department of Respiratory Medicine, Nanjing General Hospital of Nanjing Military Area Command, Nanjing, Jiangsu 210002; ${ }^{7}$ Department of Respiratory Medicine, Nanjing Chest Hospital, Medical School of Southeast University, Nanjing, Jiangsu 210029; ${ }^{8}$ Burning Rock Biotech, Guangzhou, Guangdong 510300; ${ }^{9}$ Department of Internal Medicine, Jiangsu Cancer Hospital, Nanjing, Jiangsu 210009; ${ }^{10}$ Department of Medical Oncology,
\end{abstract}

The First Affiliated Hospital of Nanjing Medical University, Jiangsu Province Hospital, Nanjing, Jiangsu 210029, P.R. China

Received September 26, 2018; Accepted June 5, 2019

DOI: $10.3892 / 01.2019 .10625$

\begin{abstract}
Currently, in clinical settings, all TP53 mutations have been considered equally. However, numerous studies have demonstrated that the position and type of mutation have differential effects on prognosis. Such discrepancy can be partially due to the lack of unifying classification system for TP53 mutations. In the present study, two of the most frequently used systems were compared, according to the location of the mutation or its functional effects on $\mathrm{p} 53$ protein and the impact of TP53 mutations on the overall survival (OS) time of 379 Chinese patients with advanced lung cancer was analyzed. Capture-based ultra-deep targeted sequencing on plasma samples of 379 patients with advanced lung cancer was performed. The present results suggested that mutations occurring in exon 8 may be associated with shorter OS in tyrosine
\end{abstract}

Correspondence to: Dr Renhua Guo, Department of Medical Oncology, The First Affiliated Hospital of Nanjing Medical University, Jiangsu Province Hospital, 300 Guangzhou Road, Nanjing, Jiangsu 210029, P.R. China

E-mail: guorenhua@csco.ac.cn

Dr Liangjun Zhu, Department of Internal Medicine, Jiangsu Cancer Hospital, 42 Baiziting Road, Nanjing, Jiangsu 210009, P.R. China E-mail: zhulj98@foxmail.com

${ }^{*}$ Contributed equally

Key words: TP53, TP53 exon mutation, lung cancer, biomarker kinase inhibitor-naïve patients $(\mathrm{P}=0.013)$ and in patients previously treated with one line of treatment $(\mathrm{P}=0.032)$. The results of the present study provided solid evidence that not all TP53 mutations were associated with a similar prognosis. Mutations in exon 8 were found in a subgroup of patients with unfavorable prognosis across various treatment histories. To the best of our knowledge, the present study is the first to compare different TP53 mutation classification systems in a large cohort of patients with advanced lung cancer.

\section{Introduction}

TP53, the first tumor suppressor gene to be identified, acts as the guardian of the genome and is involved in the regulation of several essential cell processes, including, but not limited to, cell cycle regulation, apoptosis, cell differentiation, DNA repair and blood vessel formation $(1,2)$. It is the most frequently mutated gene across a large spectrum of different types of cancer, including lung adenocarcinoma and lung squamous cell carcinoma, with a mutation rate of $\sim 50 \%$ (2-4). Under normal conditions, TP53 is rapidly degraded; however, upon cellular stress, it is activated and stabilized, resulting in protein accumulation in the nucleus $(5,6)$. The activation of the TP53 signaling pathway has been demonstrated to lead to DNA damage repair and cell cycle arrest $(7,8)$. Mutations in TP53 have been revealed to result in the loss of tumor-suppressor function, thus leading to an unstable genome and downregulating apoptosis (9). Accumulating evidence have suggested that, in addition to eliminating the tumor suppressor function, mutations in TP53 can also induce new functions, including gain-of-function mutations, which can accelerate tumor progression and metastasis $(2,9,10)$. 
TP53 mutation is observed in $~ 50 \%$ of patients with non-small cell lung cancer (NSCLC), with a higher prevalence in squamous-cell carcinoma of the lung compared with lung adenocarcinoma (38 vs. $12 \%)(11,12)$. These alterations can include frameshift, nonsense, silent and missense mutations (11-13). Unlike other tumor suppressor genes, such as $A P C, B R C A 1$ or RB transcriptional corepressor 1 $(R B 1)$ with truncating mutations being the major alteration type, the majority of TP53 alterations are missense mutations, accounting for more than $75 \%$ of alterations $(13,14)$. The majority of TP53 mutations occur in the DNA-binding region, in exons 5-8, spanning 540 nucleotides with numerous recurring hotspot mutations, leading to a stable protein with a significant loss of activity (14-17). In vitro studies have shown that wild-type (WT) p53 promotes gefitinib-induced apoptosis (18). The prognostic and predictive values of TP53 mutations have been investigated, however results are conflicting; a previous study demonstrated that non-disruptive TP53 mutations are independently correlated with shorter OS in patients with advanced NSCLC, regardless of epidermal growth factor receptor (EGFR) and KRAS status (19). Another study revealed that a shorter OS was associated with adjuvant chemotherapy in patients presenting mutations in TP53 with NSCLC and completely resected tumors (20). A previous study investigating clinical outcomes of patients with NSCLC with dual EGFR and TP53 mutations revealed lower response rates and shorter progression-free survival (PFS) in such patients compared with patients with EGFR mutations (21). By contrast, other previous studies have revealed the lack of association between TP53 mutations and OS or response to treatment (22-24). The lack of a unifying classification system may contribute to the controversy regarding the prognosis and predictive value of TP53. A variety of criteria have been used to categorize TP53 mutations, including, but not limited to, functional effects on p53 (disruptive vs. non-disruptive) $(15,17,19)$ and location ('hotspot' exons vs. 'non-hotspot' exons) $(14,17)$.

Currently, in clinical settings, all TP53 mutations have been considered equally, without major differences among the various types of mutations. However, an increasing number of studies suggested that the type and position of the mutation may be important, and the present study aimed to investigate this possibility in lung cancer. In fact, numerous studies have revealed that the position and the type of mutation have differential effects on prognosis $(2,11,17)$. Important functional differences among various mutant forms of p53 have been elucidated, including mutations in the amino-terminal (AT) domain, the oligomerization domain (OD) and the DNA-binding domain (DBD) (25-28). AT-domain mutations often result in the disruption of the expression of full-length p53 (26). Alternatively, translation from the start codon in exon 4 results in the expression of $\mathrm{p} 47$, which retains the apoptotic function of p53 (26). A previous study has suggested that sporadic human cancers with AT-domain mutations are often more responsive to treatment (26). Mutations occurring in the OD, which is important for the tetramerization of p53, often behave as loss-of-function mutations (25). Patients harboring such mutations are less responsive to therapies that rely on p53-mediated cytotoxic effects (25). In total, $80 \%$ of TP53 mutations affect the DBD, encoded by exons 5-8. In addition to the loss of functional effects, mutations in DBD can also acquire additional oncogenic properties after the loss of the WT allele $(2,28)$.
In the present study, capture-based ultra-deep targeted sequencing was performed on the plasma samples of 379 Chinese patients with advanced lung cancer to investigate clinical outcomes associated with TP53 mutations. The TP53 mutation classification systems, based on the functional effect and location of the mutation, were also compared.

\section{Materials and methods}

Patient selection. TP53 status was retrospectively analyzed and its predictive and prognostic values were examined in 379 patients with advanced lung cancer (Stage IIIB-IV) harboring at least one classic NSCLC driver mutation. Staging of the primary lung tumor, lymph node status and metastasis were assessed based on the American Joint Committee on Cancer 7th edition Tumor, Node and Metastasis (TNM) staging system of NSCLC (29). Patients (female to male ratio, 1:1.3; median age, 56.5 years; range, 26-82 years) were treated at any of the nine participating centers between September 2015 and October 2016. The inclusion criteria were: i) Patients diagnosed with advanced-stage lung cancer (stage IIIB-stage IV) of any histology harboring at least one classic NSCLC driver mutation; and ii) the patient was treated at any of the nine participating centers between September 2015 and October 2016. The exclusion criteria was patients with early-stage lung cancer (stage IA-IIIA) of any histology. Written informed consent was obtained from each patient for participation in the present study. Capture-based targeted sequencing was performed on the plasma samples using a panel consisting of 168 lung cancer-associated genes, spanning $160 \mathrm{~kb}$ of the human genome. The present study was approved by the Ethics Committee of Jiangsu Province Hospital (Nanjing, China).

Next generation sequencing library preparation and capture-based targeted DNA sequencing. Next generation sequencing was performed using a commercial panel comprising 168 lung cancer-associated genes (Lung Plasma; Burning Rock Biotech) in a Clinical Laboratory Improvement Amendments-certified laboratory as previously described (30). Briefly, circulating cell-free DNA was acquired from 4-5 ml of plasma using the QIAamp Circulating Nucleic Acid kit (Qiagen China Co., Ltd.) according to the manufacturer's protocol. A minimum of $50 \mathrm{ng}$ of DNA is required for next-generation sequencing library construction. A DNA library for the next-generation sequencing experiments were constructed. Fragments between 200 to 400 base pairs (bp) from the DNA were end-repaired, phosphorylated and ligated with adaptors (Agencourt AMPure XP kit; Beckman Coulter, CA, USA). Purified DNA with adaptors were then hybridized with capture probes baits, underwent hybrid selection with magnetic beads, and PCR amplified. The quality and the size of the fragments were assessed using a Qubit 2.0 fluorimeter (Thermo Fisher Scientific, Inc., Waltham, MA, USA) with a dsDNA high-sensitivity assay kit (Thermo Fisher Scientific, Inc.). Indexed samples were sequenced on a Nextseq500 sequencer (Illumina, Inc.) with pair-end reads. An average coverage of 11,816x was reached with a limit of detection of $0.2 \%$.

Sequence data analysis. Data were analyzed using optimized pipeline for somatic mutation calling as previously 
described (30). Briefly, the sequence data were mapped to the reference human genome (hg19) using Burrows-Wheeler Aligner (version 0.7.10) (31). Local alignment optimization and variant calling were performed using Genome Analysis Tool kit (version 3.2) (32,33) and VarScan (version 2.4.3) (34). Variants were filtered using the VarScan fpfilter pipeline; loci with depth $<100$ were filtered out. Base calling in plasma samples required $\geq 8$ supporting reads for single nucleotide variations and 5 supporting reads for insertion-deletion variations. Variants with population frequency $>0.1 \%$ in the ExAC (http://exac.broadinstitute.org/), 1,000 Genomes (35), dbSNP (https://www.ncbi.nlm.nih.gov/snp/) (36) or ESP6500SI-V2 (https://evs.gs.washington.edu/EVS/) databases were grouped as single nucleotide polymorphisms and excluded from further analysis. Remaining variants were annotated with ANNOVAR (2016-02-01 release) (37) and SnpEff (version 3.6) (38). Analysis of DNA translocation was performed using Factera (version 1.4.3) (39). Copy number variations (CNV) were analyzed based on the depth of coverage data of capture intervals using an in-house developed algorithm. The limit of detection for CNVs was 1.5 and 2.64 for deletions and amplifications, respectively.

Classification of TP53 mutations. Disruptive mutations, as described previously (15), were defined as any mutation leading to a stop codon or missense mutations occurring within the L2-L3 loop of the DNA-binding domain, leading to a substitution with an amino acid of a different polarity or charge group. All other mutations were defined as non-disruptive. Hotspot exons were defined as exons 5-8, as previously described (17).

Statistical analysis. Since the data were not equally distributed, data are presented as the median. All statistical tests were conducted in $\mathrm{R}$ version 3.3.3 (The $\mathrm{R}$ Foundation for Statistical Computing, Vienna, Austria; https://www.r-project. org) and R Studio version 1.1.383 software (40), and all tests were two-sided unless otherwise specified. Pearson's correlation test was used to assess correlation between two continuous variables. Fisher's exact test was used to assess the association between two categorical variables. Survival times were illustrated by Kaplan-Meier curves with the P-value determined by log-rank tests or Cox regression models when a co-variant was included. All survival analyses were adjusted for age, sex, smoking history, stage and histology. $\mathrm{P}<0.05$ was considered to indicate a statistically significant difference.

\section{Results}

Patient characteristics. The TP53 status of 379 patients with advanced lung cancer (Stage IIIB to IV) harboring at least one classic NSCLC driver mutation with various histological types was assessed in the present study. Among them, 294 patients had EGFR mutations, 24 had anaplastic lymphoma kinase $(A L K)$ rearrangements, 14 had erb-b2 receptor tyrosine kinase 2 mutations, five had MET Proto-Oncogene (MET) mutations, two had B-raf proto-oncogene mutations, four had ROS proto-oncogene 1, receptor tyrosine kinase fusions, 11 had KRAS fusions and five had ret proto-oncogene fusions; the remaining 20 patients had dual driver mutations (Table I). In the examined cohort, 213 (56.2\%) were female and 166
(43.8\%) were male patients, and 156 had a history of smoking. The median age of this cohort was 56.5 years, ranging between 26 and 82 years. The cohort primarily consisted of adenocarcinoma (332/379), followed by squamous cell carcinoma (SqCC) (11/379) and small cell lung cancer (10/379). A total of 165 patients $(43.5 \%)$ had not received tyrosine kinase inhibitors (TKI) as a treatment regimen and were considered TKI-naïve; among them, 84 were treatment-naïve and the remaining were previously treated with chemotherapy. A total of 214 patients $(56.5 \%)$ were previously treated with TKI; among them, 184 patients were previously treated with one line of treatment. A total of 173 patients were treated with EGFR-TKI and the remaining 11 were treated with crizotinib, an ALK inhibitor (41). A total of 30 patients received two lines of treatment. Among them, 24 were treated with first and third generation EGFR-TKIs, two patients were treated with first generation EGFR-TKIs followed by a tyrosine-protein kinase MET inhibitor and the remaining three patients were treated with ALK inhibitors, Crizotinib followed by ceritinib (41). Table I summarized the detailed clinical characteristics of the cohort investigated.

TP53 mutation prevalence and associations with clinical parameters. A capture-based ultra-deep targeted sequencing analysis was performed as described in Materials and methods and (30) on the plasma samples obtained from 379 patients with advanced lung cancer to investigate their TP53 status and the prognostic value of the TP53 mutations. The prevalence of TP53 mutations in the cohort was $49.9 \%(189 / 379)$, which is comparable to its prevalence in the western population (22). Among them, 163 patients harbored mutations in hotspot exons: 48 Mutations were on exon 5, 31 on exon 6, 40 on exon 7 and 46 on exon 8 (Table I). Two patients had two TP53 mutations (data not shown). A total of 84 patients had disruptive mutations. The distribution of TP53 mutations is also presented in Fig. S1. No association between TP53 mutations and smoking history was observed when all TP53 mutations were taken into consideration (data not shown). The examined cohort primarily consisted of patients with adenocarcinoma, squamous cell carcinoma or small cell lung cancer. The percentages of TP53 mutations were comparable in patients with adenocarcinoma (48.3\%) and small cell lung cancer (48.4\%) (data not shown). All patients investigated in the present study with small cell lung cancer carried TP53 mutations, in line with previous studies (42), suggesting that a significant percentage of patients with small cell lung cancer have TP53 mutations. Next, the mutation spectra of patients with TP53 mutations were compared with patients without TP53 mutation (Fig. S2). The present results revealed that the most frequent mutation was $E G F R$ in both groups. In addition, a larger number of $R B 1$ mutations and MET amplifications were present in patients with TP53 mutation (Fig. S2).

The correlations between TP53 mutations, classified according to different systems, and clinical parameters, including but not limited to the TNM stage, smoking history and metastatic sites were further investigated. A positive correlation was identified between TP53 mutations and the TNM stage when all mutations were considered collectively. Patients with TP53 mutations were more likely to have advanced $\mathrm{N}$ $(\mathrm{P}=0.004, \mathrm{r}=0.161)$ and $\mathrm{M}(\mathrm{P}=0.004, \mathrm{r}=0.151)$ stages of the 
Table I. Patient demographics and clinical characteristics.

\begin{tabular}{|c|c|}
\hline Characteristics & Value \\
\hline Total, n & 379 \\
\hline \multicolumn{2}{|l|}{ Sex } \\
\hline Male, n (\%) & $166(43.8)$ \\
\hline Female, n (\%) & $213(56.2)$ \\
\hline Age, median (range) & 56.5 years $(26-82$ years $)$ \\
\hline \multicolumn{2}{|l|}{ Smoking history } \\
\hline Smokers, n (\%) & $156(41.2)$ \\
\hline Non-smokers, n (\%) & $200(52.8)$ \\
\hline No data, n (\%) & $39(10.3)$ \\
\hline \multicolumn{2}{|l|}{ Histology } \\
\hline Adenocarcinoma, n (\%) & $332(87.5)$ \\
\hline Squamous cell carcinoma, n (\%) & $11(2.9)$ \\
\hline Small cell lung cancer, n (\%) & $10(2.64)$ \\
\hline Others, n $(\%)$ & $26(6.9)$ \\
\hline \multicolumn{2}{|l|}{ Treatment History } \\
\hline TKI-naïve, n (\%) & $165(43.5)$ \\
\hline One line of TKI treatment, n (\%) & $184(48.5)$ \\
\hline EGFR-TKIs, n (\%) & $173(94)$ \\
\hline ALK-TKIs, n (\%) & $11(6)$ \\
\hline Two lines of TKI treatment, $\mathrm{n}(\%)$ & $30(8)$ \\
\hline 1st and 3rd EGFR-TKI, n (\%) & $24(80)$ \\
\hline EGFR-TKI and c-MET-TKI, n (\%) & $3(10)$ \\
\hline ALK-TKIs, n (\%) & $3(10)$ \\
\hline \multicolumn{2}{|l|}{ TP53 status, n (\%) } \\
\hline WT, n (\%) & $190(50.1)$ \\
\hline Mutated, n (\%) & 189 (49.9) \\
\hline Disruptive mutation, n (\%) & $84(44.4)$ \\
\hline Non-disruptive mutation, n (\%) & $105(55.6)$ \\
\hline Exon 5, n (\%) & $48(25.4)$ \\
\hline Exon 6, n (\%) & $31(16.4)$ \\
\hline Exon 7, n (\%) & $40(21.2)$ \\
\hline Exon 8, n (\%) & $46(24.3)$ \\
\hline \multicolumn{2}{|l|}{ Driver mutation } \\
\hline$E G F R, \mathrm{n}(\%)$ & 294 (77.6) \\
\hline$A L K, \mathrm{n}(\%)$ & $24(6.3)$ \\
\hline$E R B B 2, \mathrm{n}(\%)$ & $14(3.7)$ \\
\hline$M E T, \mathrm{n}(\%)$ & $5(1.3)$ \\
\hline$B R A F, \mathrm{n}(\%)$ & $2(0.5)$ \\
\hline$R O S 1, \mathrm{n}(\%)$ & $4(0.1)$ \\
\hline$K R A S, \mathrm{n}(\%)$ & $11(2.9)$ \\
\hline$R E T, \mathrm{n}(\%)$ & $5(1.3)$ \\
\hline Dual drivers, n (\%) & $20(5.3)$ \\
\hline
\end{tabular}

TKI, tyrosine kinase inhibitor; WT, wild-type; ALK, anaplastic lymphoma kinase; EGFR, epidermal growth factor receptor; ERBB2, erb-b2 receptor tyrosine kinase 2; MET, MET proto-oncogene, receptor tyrosine kinase; ROS1, ROS proto-oncogene 1, receptor tyrosine kinase; RET, ret proto-oncogene.

disease (Fig. 1A and B). A positive correlation was also identified between liver metastasis and TP53 mutations when all mutations were considered collectively $(\mathrm{P}=0.001, \mathrm{r}=0.187)$. In the cohort, $67.9 \%$ patients $(55 / 81)$ with TP53 mutations had liver metastasis; in contrast, $45.5 \%$ (127/279) of patients without a TP53 mutation had liver metastasis $(\mathrm{P}=0.001)$ (Fig. 1C). These trends also existed when TP53 mutations were classified according to the location of the mutation or functional effects on the p53 protein. Hotspot exon and non-hotspot exon mutations demonstrated a significant correlation with $\mathrm{N}$ $(\mathrm{P}=0.036$ and 0.012 , respectively) and $\mathrm{M}(\mathrm{P}=0.012$ and 0.001 , respectively) stage (data not shown). When TP53 mutations were classified as disruptive or non-disruptive mutations, TP53 disruptive mutations exhibited a non-significant correlation with $\mathrm{N}(\mathrm{P}=0.08)$ and $\mathrm{M}(\mathrm{P}=0.1)$ stages. A strong correlation was observed between liver metastasis and TP53 mutation, regardless of the classification system $(\mathrm{P}<0.001)$. Only TP53 hotspot exon mutations were significantly correlated with bone metastasis $(\mathrm{P}=0.032)$ (data not shown). Collectively, the present results suggested that only certain types of TP53 mutations were correlated with the clinical parameters analyzed, providing evidence for the hypothesis that not all TP53 mutations are equal.

Prognostic values of TP53 mutations. Conflicting findings regarding the prognostic values of the TP53 status were reported, which can be partially attributed to the lack of a unifying classification system (21-24). The prognostic value of TP53 mutations was evaluated using the two aforementioned classification systems. Patients were grouped into three groups based on their treatment history: i) TKI-naïve $(n=165)$; ii) previously treated with one line of TKI $(n=184)$; and iii) treated with $\geq 2$ TKI $(n=30)$. In the TKI-naïve patients, 74 patients had TP53 mutations. Among them, 64 had mutations in hotspot exons (exons 5-8) $(2,28)$ and the remaining 10 had mutations in other exons. A total of 33 patients had disruptive mutations and 45 had non-disruptive mutations. No association was observed between TP53 mutations and OS when all TP53 mutations were considered collectively or classified according to their location (hotspot exon vs. non-hotspot exon mutations) and functional effects on p53 protein (disruptive vs. non-disruptive; Fig. 2A-C). Notably, mutations occurring on exon 8 were found to be associated with OS $(\mathrm{P}=0.013)$ when controlling for age, sex, stage and histology. A total of 14 patients with mutations in exon 8 had a shorter median OS compared with the remaining 91 patients who had no mutations in exon 8 (Fig. 2D).

In patients previously treated with one line of TKI treatment $(n=184)$, an analysis revealed that TP53 status, when all mutations were considered collectively, was found to be marginally associated with OS $(\mathrm{P}=0.05)$. Patients with TP53 mutations had a shorter OS compared with patients with WT TP53 (Fig. 3A). Such associations were significantly enhanced when only mutations occurring on exon 8 were considered $(\mathrm{P}=0.032$; Fig. 3B). A total of 26 patients had mutations in exon 8 , including 22 missense, three frameshift and one nonsense mutation (Fig. 3B). However, when all hot exon mutations were considered collectively, no association was observed ( $\mathrm{P}=0.083$; Fig. 3C). The same trend was observed in TKI-naïve patients, disruptive $(\mathrm{P}=0.081)$ and non-disruptive $(\mathrm{P}=0.106)$ mutations were not significantly associated with OS (Fig. 3D). 

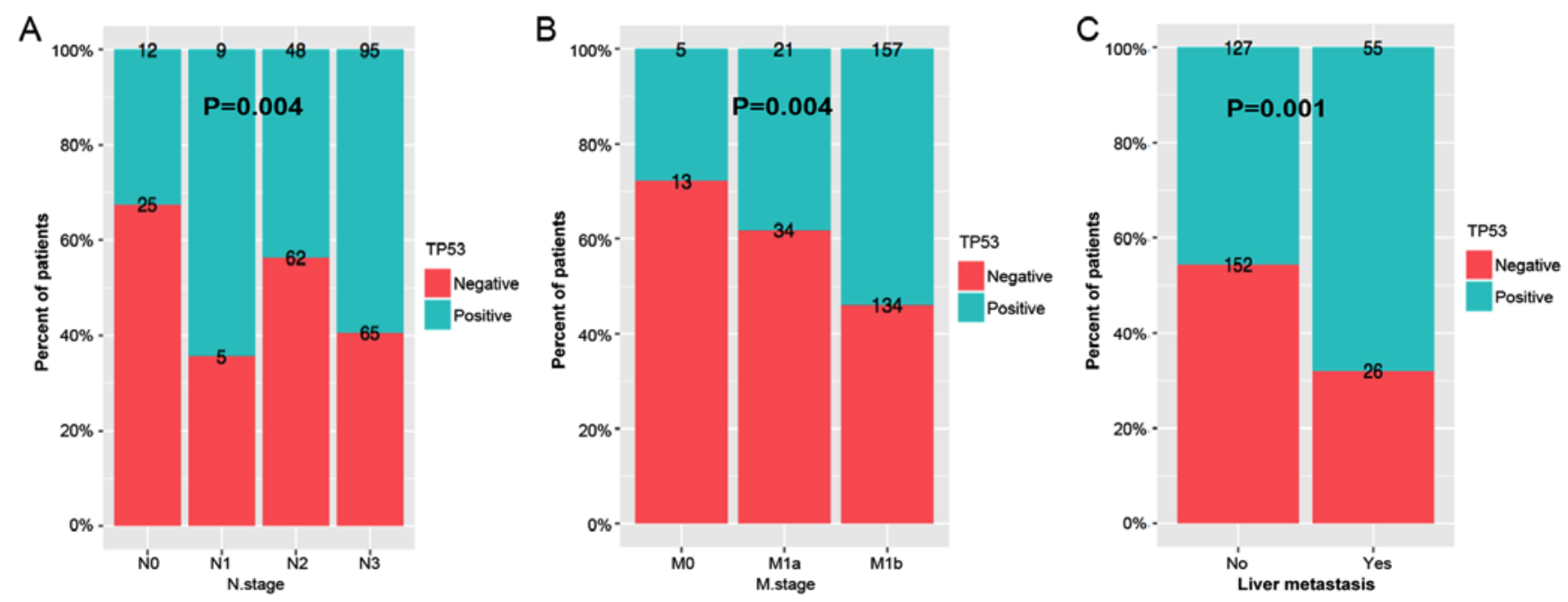

Figure 1. Correlations between TP53 status and clinical parameters. Patients with TP53 mutations are more likely to have more advanced (A) N and (B) M stage as well as (C) liver metastasis. Blue bars denote patients with mutations in TP53 and red bars denote patients with wild-type TP53. Pearson's correlation coefficient test was used to determine P-values. TNM, Tumor-Node-Metastasis.

A
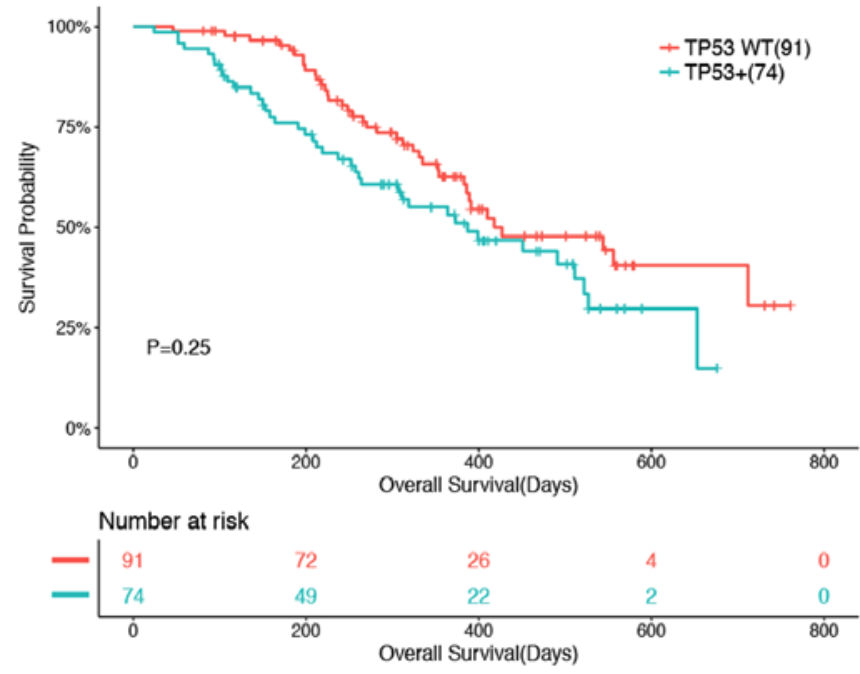

C
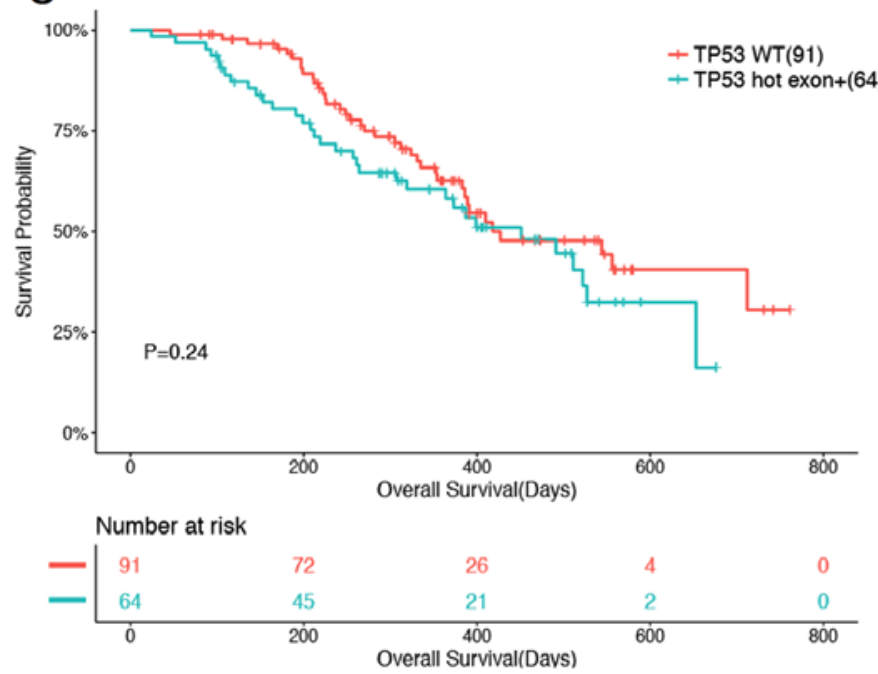

B
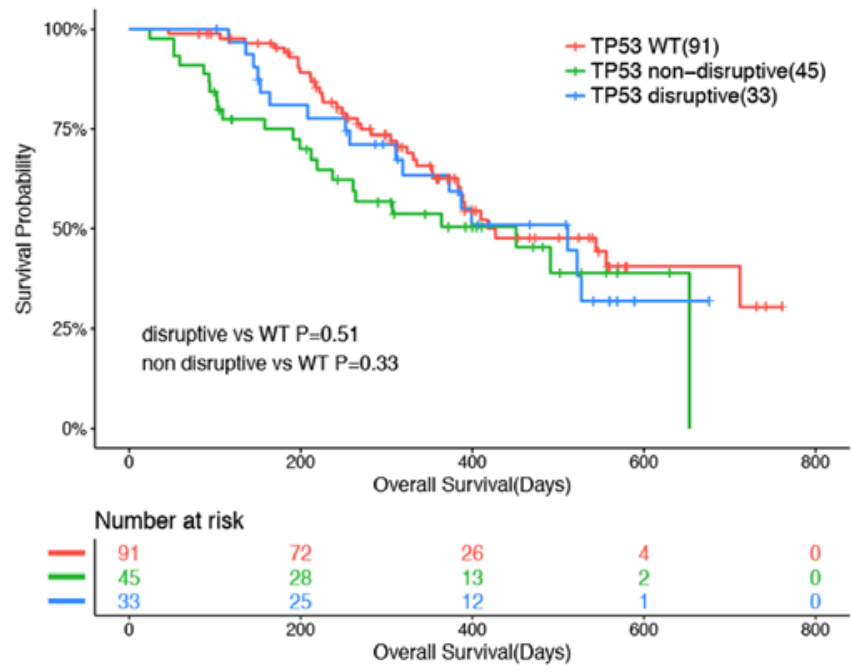

D

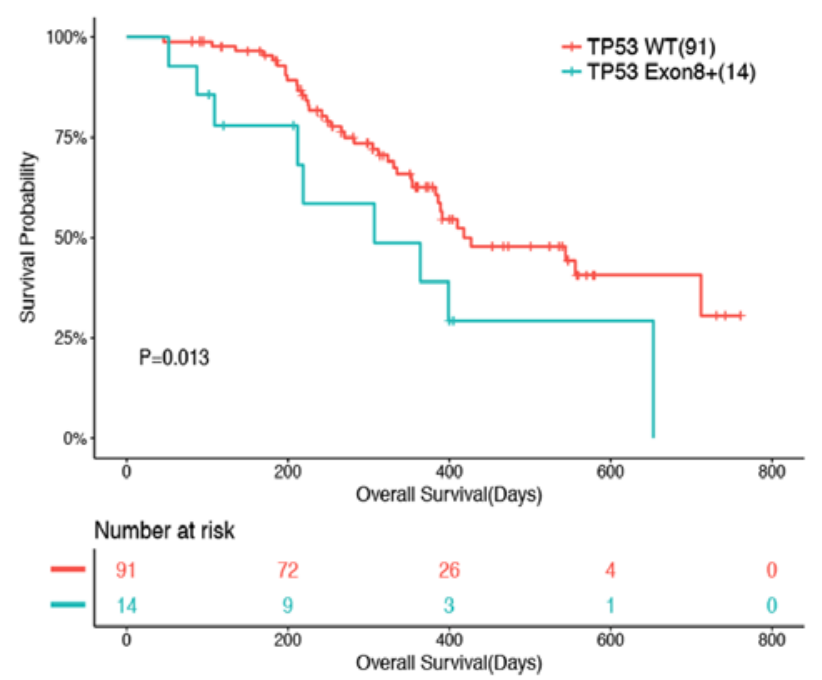

Figure 2. Associations between TP53 mutations and survival outcomes in TKI-naïve patients. Kaplan-Meier curves comparing OS in (A) patients with WT and mutant TP53, (B) patients with WT TP53 and disruptive and non-disruptive TP53 mutations, (C) patients with WT TP53 and hotspot exon mutations, and (D) patients with WT TP53 and mutations occurring on exon 8. TKI, tyrosine kinase inhibitor; OS, overall survival; WT, wild-type. 
A
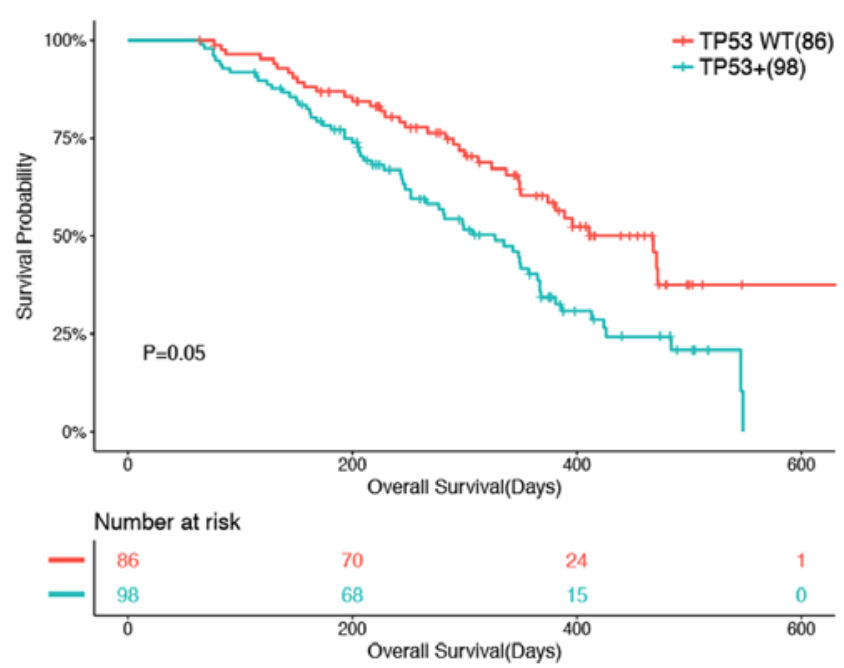

C
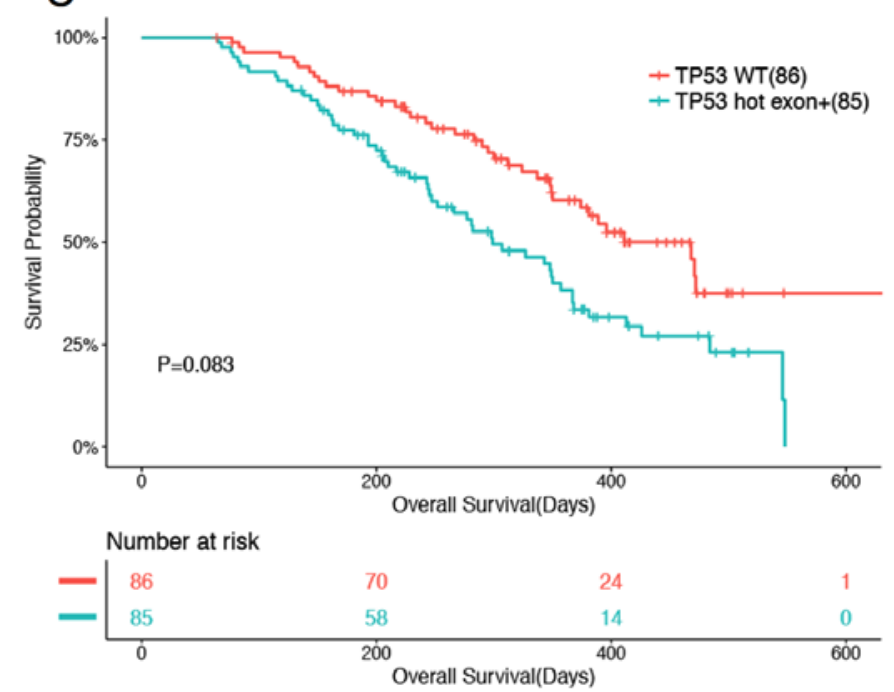

B
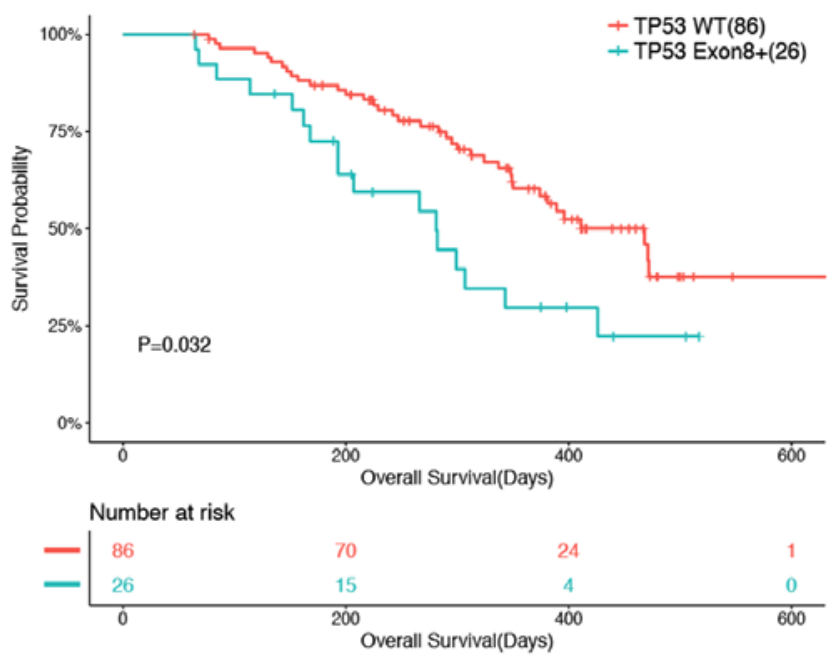

D
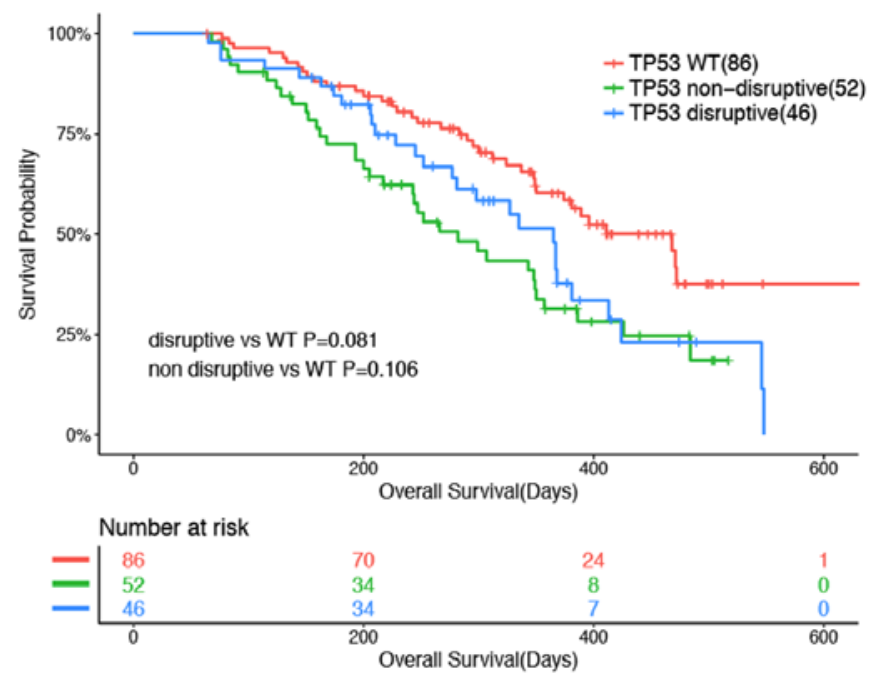

Figure 3. Associations between TP53 mutations and survival outcomes in patients who had one course of TKI treatment. Kaplan-Meier curves comparing OS in (A) patients with WT and mutant TP53, (B) patients with WT TP53 and mutations occurring on exon 8, (C) patients with WT TP53 and hotspot exon mutations, and (D) patients with WT TP53, and disruptive and non-disruptive TP53 mutations. TKI, tyrosine kinase inhibitor; OS, overall survival; WT, wild-type.

In the cohort, 99 patients were undergoing osimertinib treatment, a third-generation EGFR TKI (43). The impact of TP53 mutations on OS in osimertinib-treated patients was subsequently analyzed. In this cohort, 32 patients had WT TP53 and 67 patients had TP53 mutations (data not shown). No association was observed between TP53 status and OS, regardless of the classification system (data not shown). In the examined cohort of patients, 62 patients possessed EGFR 19 del and 37 possessed EGFR L858R (data not shown). No association was observed between TP53 status and OS, regardless of classification system, in patients harboring EGFR L858R (data not shown). In patients harboring EGFR 19 del concurrent to T790M treated with osimertinib, non-disruptive mutations $(\mathrm{P}=0.031)$ were found to be associated with OS (Fig. 4A). A total of 14 patients with non-disruptive TP53 mutations exhibited a significantly shorter OS compared with patients with WT TP53. All TP53 mutations $(\mathrm{P}=0.156)$, particularly disruptive mutations $(\mathrm{P}=0.690)$ as well as all hotspot exon mutations $(\mathrm{P}=0.128)$ including exon 8 $(\mathrm{P}=0.075)$ did not exhibit an association with OS (Fig. 4).
In patients treated with two lines of TKI, the analysis revealed that TP53 mutations, when considered collectively, were identified to be associated with $\mathrm{OS}(\mathrm{P}=0.037$; Fig. $5 \mathrm{~A})$. Mutations occurring on exon $8(\mathrm{P}=0.079)$ as well as all hot exon mutations $(\mathrm{P}=0.052)$ also exhibited an association with OS (Fig. 5B and C). In contrast, disruptive mutations $(\mathrm{P}=0.086)$ did not exhibit an association with OS, whereas non-disruptive mutations $(\mathrm{P}=0.048)$ exhibited a marginal association with OS (Fig. 5D). All analyses were controlled for smoking status. Collectively, the data provided evidence supporting the hypothesis that TP53 mutations are not equal. Furthermore, by comparing multiple TP53 mutation classification systems, it was identified that mutations in exon 8 may serve as prognostic biomarkers across all patients.

\section{Discussion}

In the present study, the association between TP53 mutations, analyzed using two classification methods (based on location 
A
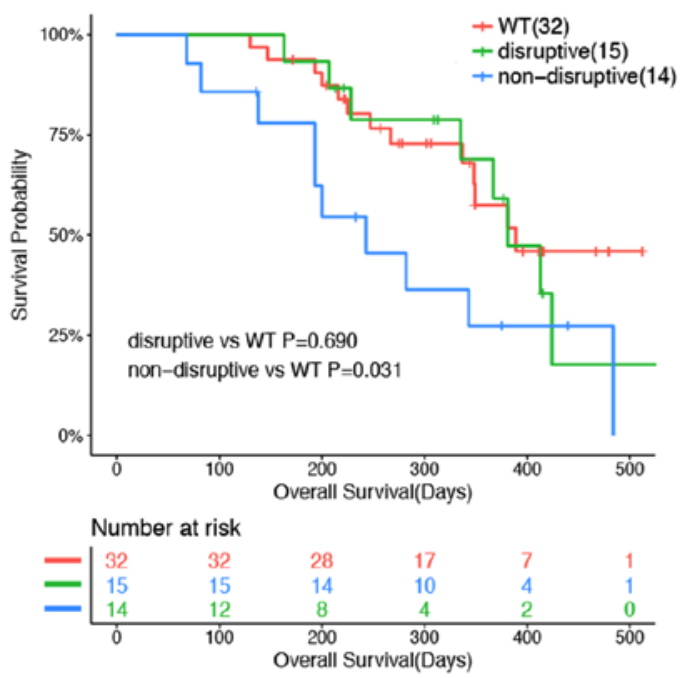

C
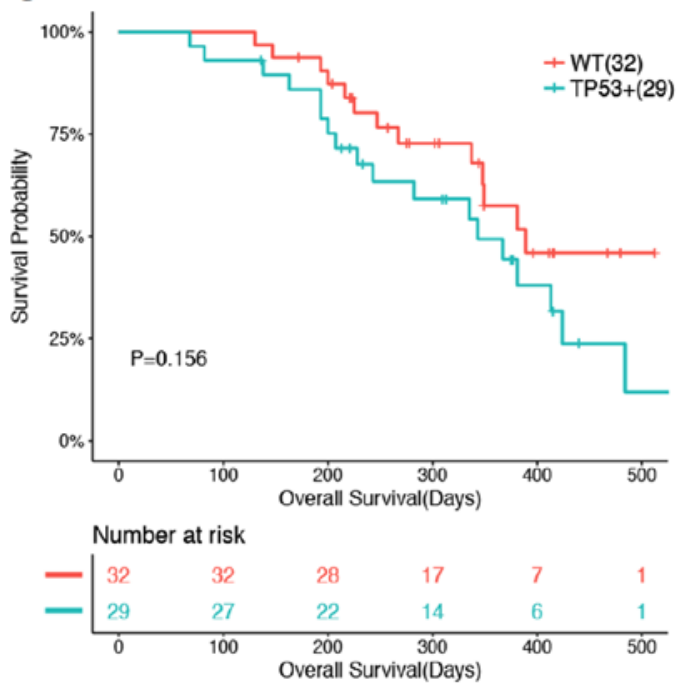

B
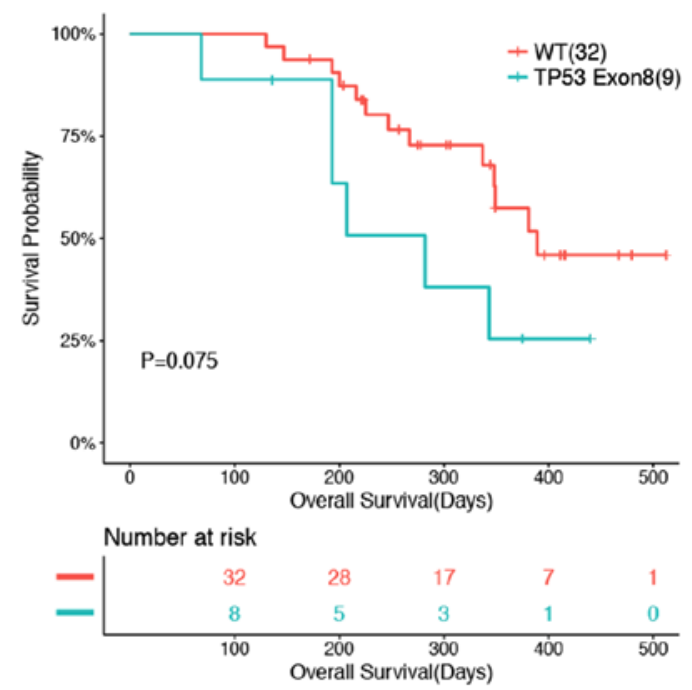

D
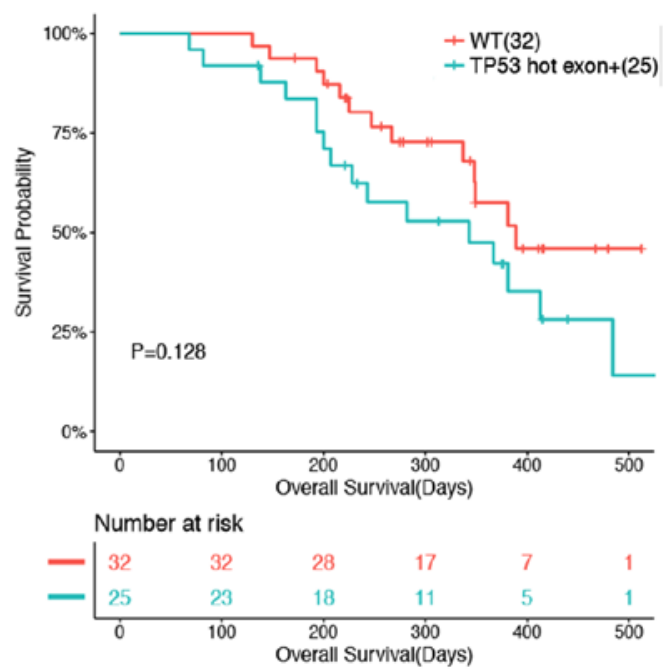

Figure 4. Associations between TP53 mutations and survival outcomes in patients harboring EGFR 19 del in conjunction with EGFR T790M undergoing osimertinib treatment. Kaplan-Meier curves comparing OS in (A) patients with disruptive and non-disruptive TP53 mutations, (B) patients with WT TP53 and mutations occurring on exon 8, (C) patients with WT and mutant TP53, and (D) patients with WT TP53 and hotspot exon mutations. TKI, tyrosine kinase inhibitor; OS, overall survival; WT, wild-type.

and function), and OS was investigated in a large cohort of patients with advanced lung cancer. It was demonstrated that mutations occurring on exon 8 may serve as prognostic biomarkers across all patients regardless of treatment history. The present results revealed that mutations occurring in exon 8 correlated with shorter OS in TKI-naïve and patients previously treated with one line of TKI. Such mutations also exhibited a slight association, although not significant, with shorter OS in patients previously treated with two lines of treatment. Therefore, TP53 exon 8 mutations defined a distinct subset of patients with an unfavorable prognosis. The association between OS and TP53 mutations categorized by function or considered collectively was not consistent across various treatment histories. In fact, TP53 mutations considered collectively were only associated with OS in patients who received a certain treatment. TP53 mutations were not associated with the prognosis in treatment-naïve patients. Such inconsistencies could be attributed to the following reasons: i) Not all mutations occurring on hotspot exons (exons 5-8) are functional; ii) treatment history of treated patients may vary among patients; iii) the number of patients were significantly fewer in patients treated with $\geq 2$ lines of treatment; and iv) a number of studies have reported that TP53 can serve as a resistance mechanism against the function of EGFR inhibitors (17,21,44-46). Therefore, the impact of mutations in TP53 in patients treated with such inhibitors may be greater compared with patients treated with other therapies, such as chemotherapy. However, further examination is required as to why mutations occurring on exon 8 are associated with unfavorable prognoses. Therefore, exon 8 mutations that potentially serve as prognostic biomarkers require validation in larger cohorts.

Currently, all TP53 mutations are considered equally in clinical settings, as well as during the development of therapeutic strategies, which primarily focuses on the restoration of 
A
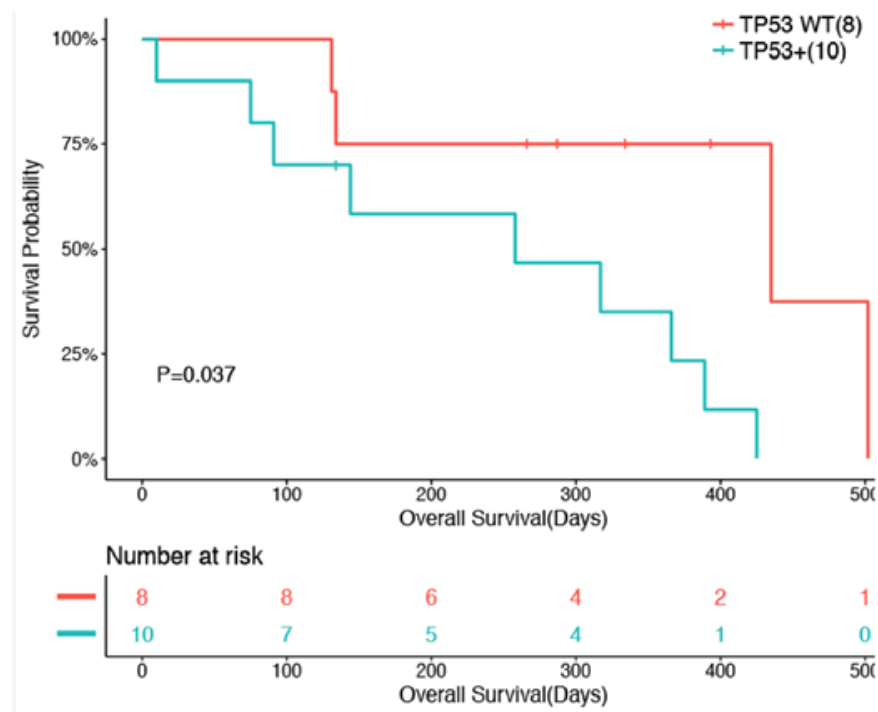

C
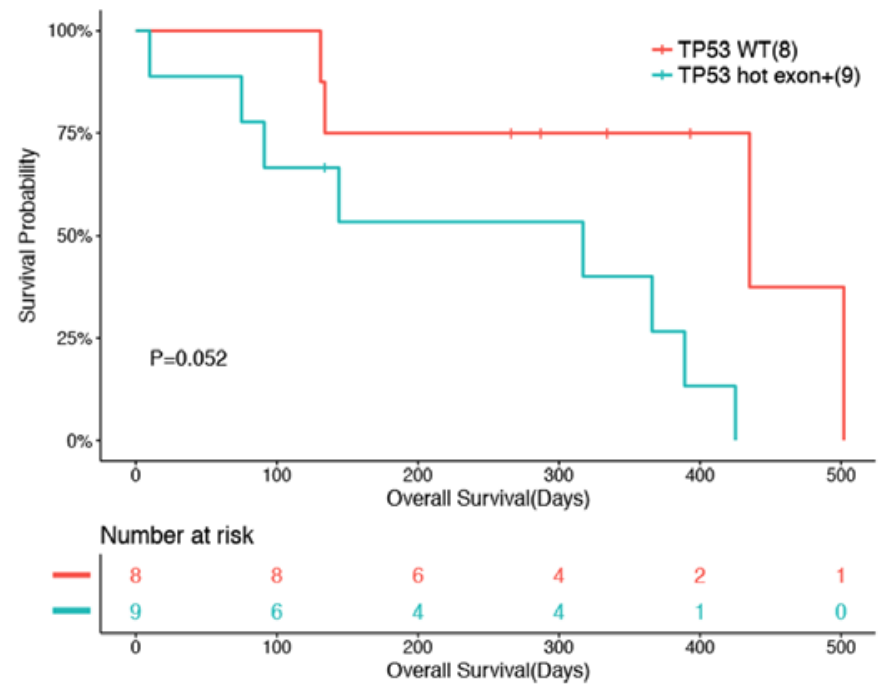

B
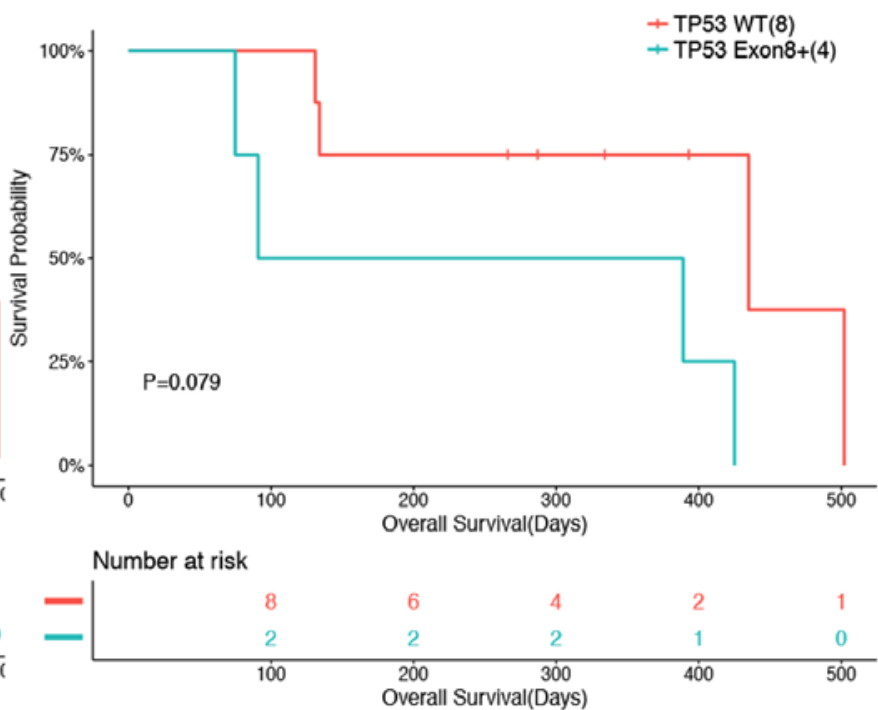

D
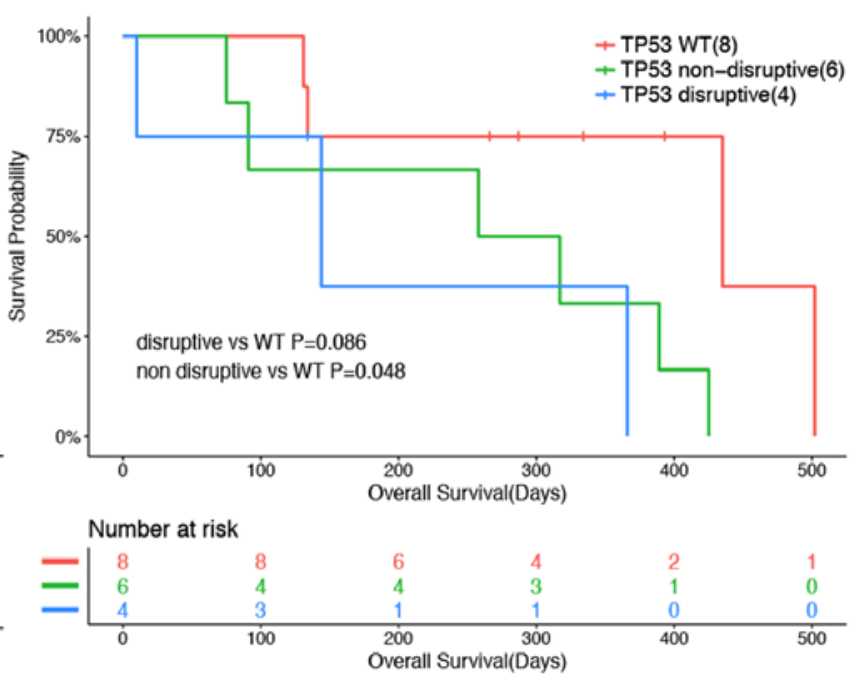

Figure 5. Associations between TP53 mutations and survival outcomes in patients who received two lines of TKI treatment. Kaplan-Meier curves comparing OS in (A) patients with WT and mutant TP53, (B) patients with WT TP53 and mutations occurring on exon 8, (C) patients with WT TP53 and hotspot exon mutations, and (D) patients with WT TP53, and disruptive and non-disruptive TP53 mutations. TKI, tyrosine kinase inhibitor; OS, overall survival; WT, wild-type.

the WT activity of TP53 (47). Numerous studies investigating the prognostic value of TP53 mutations, when all mutations were considered collectively, identified either no or slight associations, which was subsequently lost in the multivariate analysis $(22,48)$. An increasing number of studies have been categorizing TP53 mutations based on the multiple biological effects produced by different mutant proteins $(15,49)$. Notably, the present study strongly followed the aforementioned approach. Several previous studies categorized TP53 mutations and examined their prognostic value, presenting conflicting results, partially due to the lack of a unifying classification system $(19,22,50)$. A number of studies reported shorter OS in the presence of specific mutations, including non-disruptive mutations (19), truncated, structural and DNA-binding mutations (51) or mutations occurring in certain exons $(52,53)$. Other studies did not identify an association in patients with lung cancer $(22-24,54)$. Some studies have demonstrated that non-disruptive mutations, allowing the maintenance of functional properties, are associated with gain-of-function properties $(55,56)$. Furthermore, mutations occurring on different parts of the gene have different biological functions such as the AT domain, DBD and oligomerization domain (25-28). Studies have shown that mutations occurring in the L2 and L3 domains, providing for DNA contacts, are associated with poor prognosis $(2,28,53)$. Due to the discrepancies identified in previous studies, the development of a clinically relevant unifying classification system is required. To the best of our knowledge, the present study is the first that compared the two classification systems commonly used (based on the position and the type of mutation) in a large cohort.

Since a significant percentage of patients exhibiting mutations in EGFR have concurrent TP53 mutations, numerous studies have also assessed the impact of TP53 mutations on the clinical outcomes of patients with EGFR mutations treated 
with EGFR-TKIs (17,21,44-46). Such studies also yielded conflicting results. A previous study revealed that the predictive and prognostic power of TP53 status to first-generation EGFR-TKI treatment are more reliable in patients harboring EGFR exon 19 deletion (19 del) (17). Since TP53 mutations have been confirmed as a primary resistance mechanism to EGFR-TKI, some studies reported diminished responses. Canale et al (17) revealed that TP53 exon 8 mutations, especially in conjunction with EGFR 19 deletion, were associated with a significantly lower disease control rate. Labbé et al (21) reported a marginally lower response rate and shorter PFS in patients with concurrent EGFR and TP53 mutations, where all TP53 mutations were considered collectively. Collectively, these previous reports and the present study suggest that the use of a unifying classification system may be important in clinical settings.

Furthermore, the majority of studies examining the clinical relevance of TP53 were primarily conducted in patients with early stage lung cancer and resectable tumors $(20,24,57)$. To the best of our knowledge, a few studies investigated patients with advanced lung cancer and a majority of them included a limited number of patients $(17,19,21,45,54,58)$. To the best of our knowledge, the present study is the first study to investigate, in a large cohort, the clinical relevance of TP53 mutations in Chinese patients with advanced lung cancer, who had received previous treatments. Furthermore, to the best of our knowledge, the present study is also the first one to investigate the association between TP53 mutations and OS in patients treated with osimertinib, a TKI inhibitor. It was revealed that the prognostic power of TP53 mutations only existed in patients with EGFR 19 del and T790M. In such patients, non-disruptive mutations were associated with shorter OS. The prognostic power was not statistically significant in patients harboring $E G F R$ L858R. A previous study evaluated the impact of TP53 mutations on the outcomes of patients with EGFR mutations treated with one course of EGFR-TKI and revealed similar results (17). Patients harboring concurrent mutations in the exon 8 of TP53 and EGFR 19 del were associated with a shorter PFS and OS. The predictive and prognostic power was much weaker in subgroups containing patients with other EGFR mutations (17). One major limitation associated with the present study is that it only included patients with classic NSCLC driver mutations. Further examination is required in order to validate these findings in larger cohorts, including patients without NSCLC driver mutations.

The results of the present study suggested that not all TP53 mutations are equal. Mutation in exon 8 can identify a subgroup of patients with unfavorable prognoses across diverse treatment group. To the best of our knowledge, the present study is the first one that compared different TP53 mutation classification systems in a large cohort of patients with advanced lung cancer. Furthermore, to the best of our knowledge, the current study may be the first to reveal that the prognostic potential of TP53 mutations, in patients treated with osimertinib, only exists in patients with EGFR 19 del mutation. Further studies are required to elucidate why TP53 mutations determined significantly poor prognoses in patients harboring EGFR 19 del but not in patients presenting EGFR L858R. The present study may provide novel insights into the identification of the most optimal treatment strategy.

\section{Acknowledgements}

Not applicable.

\section{Funding}

The present study was supported by the Wu Jieping Medical Foundation (grant no. 320.6750.17281).

\section{Availability of data and materials}

The datasets used and/or analyzed during the current study are available from the corresponding author on reasonable request.

\section{Authors' contributions}

RG, LZ, YL and FX conceived and designed the study. YL, FX, YW, QW, BW, YY, YZ, JL, ZZ, XM and LZ collected the data. JY performed the statistical analysis of the data. YL, FX, YW, QW, BW, YY, YZ, HHZ, JY and LZ analyzed and interpreted the data. HHZ, RG, LZ, YL, FX and LZ wrote the manuscript. All authors approved the final version of the manuscript and are accountable for all aspects of the work.

\section{Ethics approval and consent to participate}

All procedures performed involving human subjects were in accordance with the ethical standards of the Medical Ethics Committee of Jiangsu Province Hospital (Nanjing, China). All patients provided written informed consent for participating in the study.

\section{Patient consent for publication}

Not applicable.

\section{Competing interests}

HHZ, JZ, LZ, ZZ and JL are employees of Burning Rock Biotech. The other authors declare that they have no competing interests.

\section{References}

1. Menendez D, Inga A and Resnick MA: The expanding universe of p53 targets. Nat Rev Cancer 9: 724-737, 2009.

2. Sabapathy K and Lane DP: Therapeutic targeting of p53: All mutants are equal, but some mutants are more equal than others. Nat Rev Clin Oncol 15: 13-30, 2018.

3. Lawrence MS, Stojanov P, Mermel CH, Robinson JT, Garraway LA, Golub TR, Meyerson M, Gabriel SB, Lander ES and Getz G: Discovery and saturation analysis of cancer genes across 21 tumour types. Nature 505: 495-501, 2014.

4. Bouaoun L, Sonkin D, Ardin M, Hollstein M, Byrnes G, Zavadil J and Olivier M: TP53 variations in human cancers: New lessons from the IARC TP53 database and genomics data. Hum Mutat 37: 865-876, 2016.

5. Bieging KT, Mello SS and Attardi LD: Unravelling mechanisms of p53-mediated tumour suppression. Nat Rev Cancer 14: 359-370, 2014.

6. Kruiswijk F, Labuschagne $\mathrm{CF}$ and Vousden KH: p53 in survival, death and metabolic health: A lifeguard with a licence to kill. Nat Rev Mol Cell Biol 16: 393-405, 2015.

7. Vogelstein B, Lane D and Levine AJ: Surfing the p53 network. Nature 408: 307-310, 2000. 
8. Merkel O, Taylor N, Prutsch N, Staber PB, Moriggl R, Turner SD and Kenner L: When the guardian sleeps: Reactivation of the p53 pathway in cancer. Mutat Res 773: 1-13, 2017.

9. Muller PA and Vousden KH: p53 mutations in cancer. Nat Cell Biol 15: 2-8, 2013

10. Freed-Pastor WA and Prives C: Mutant p53: One name, many proteins. Genes Dev 26: 1268-1286, 2012.

11. Petitjean A, Achatz MI, Borresen-Dale AL, Hainaut P and Olivier M: TP53 mutations in human cancers: Functional selection and impact on cancer prognosis and outcomes. Oncogene 26: 2157-2165, 2007.

12. Fong KM, Kida Y, Zimmerman PV, Ikenaga M and Smith PJ: Loss of heterozygosity frequently affects chromosome $17 \mathrm{q}$ in non-small cell lung cancer. Cancer Res 55: 4268-4272, 1995.

13. Olivier M, Eeles R, Hollstein M, Khan MA, Harris CC and Hainaut P: The IARC TP53 database: New online mutation analysis and recommendations to users. Hum Mutat 19: 607-614, 2002.

14. Baugh EH, Ke H, Levine AJ, Bonneau RA and Chan CS: Why are there hotspot mutations in the TP53 gene in human cancers? Cell Death Differ 25: 154-160, 2018.

15. Poeta ML, Manola J, Goldwasser MA, Forastiere A, Benoit N, Califano JA, Ridge JA, Goodwin J, Kenady D, Saunders J, et al: TP53 mutations and survival in squamous-cell carcinoma of the head and neck. N Engl J Med 357: 2552-2561, 2007.

16. Lehmann BD and Pietenpol JA: Targeting mutant p53 in human tumors. J Clin Oncol 30: 3648-3650, 2012.

17. Canale M, Petracci E, Delmonte A, Chiadini E, Dazzi C, Papi M, Capelli L, Casanova C, De Luigi N, Mariotti M, et al: Impact of TP53 mutations on outcome in EGFR-mutated patients treated with first-line tyrosine kinase inhibitors. Clin Cancer Res 23 2195-2202, 2017

18. Rho JK, Choi YJ, Ryoo BY, Na II, Yang SH, Kim CH and Lee JC: p53 enhances gefitinib-induced growth inhibition and apoptosis by regulation of Fas in non-small cell lung cancer. Cancer Res 67: 1163-1169, 2007.

19. Molina-Vila MA, Bertran-Alamillo J, Gascó A, Mayo-de-las-Casas C, Sánchez-Ronco M, Pujantell-Pastor L, Bonanno L, Favaretto AG, Cardona AF, Vergnenègre A, et al Nondisruptive p53 mutations are associated with shorter survival in patients with advanced non-small cell lung cancer. Clin Cancer Res 20: 4647-4659, 2014.

20. Ma X, Le Teuff G, Lacas B, Tsao MS, Graziano S, Pignon JP, Douillard JY, Le Chevalier T, Seymour L, Filipits M, et al Prognostic and predictive effect of TP53 mutations in patients with non-small cell lung cancer from adjuvant cisplatin-based therapy randomized trials: A LACE-Bio pooled analysis. J Thorac Oncol 11: 850-861, 2016.

21. Labbé C, Cabanero M, Korpanty GJ, Tomasini P, Doherty MK, Mascaux C, Jao K, Pitcher B, Wang R, Pintilie M, et al: Prognostic and predictive effects of TP53 co-mutation in patients with EGFR-mutated non-small cell lung cancer (NSCLC). Lung Cancer 111: 23-29, 2017.

22. Scoccianti C, Vesin A, Martel G, Olivier M, Brambilla E, Timsit JF, Tavecchio L, Brambilla C, Field JK and Hainaut $P$ European Early Lung Cancer Consortium: Prognostic value of TP53, KRAS and EGFR mutations in nonsmall cell lung cancer: The EUELC cohort. Eur Respir J 40: 177-184, 2012

23. Lee SY, Jeon HS, Hwangbo Y, Jeong JY, Park JY, Lee EJ, Jin G, Shin KM, Yoo SS, Lee J, et al: The influence of TP53 mutations on the prognosis of patients with early stage non-small cell lung cancer may depend on the intratumor heterogeneity of the mutations. Mol Carcinog 54: 93-101, 2015.

24. Ma X, Rousseau V, Sun H, Lantuejoul S, Filipits M, Pirker R, Popper H, Mendiboure J, Vataire AL, Le Chevalier T, et al: Significance of TP53 mutations as predictive markers of adjuvant cisplatin-based chemotherapy in completely resected non-small-cell lung cancer. Mol Oncol 8: 555-564, 2014.

25. Lomax ME, Barnes DM, Hupp TR, Picksley SM and Camplejohn RS: Characterization of p53 oligomerization domain mutations isolated from Li-Fraumeni and Li-Fraumeni like family members. Oncogene 17: 643-649, 1998.

26. Phang BH, Othman R, Bougeard G, Chia RH, Frebourg T, Tang CL, Cheah PY and Sabapathy K: Amino-terminal p53 mutations lead to expression of apoptosis proficient p47 and prognosticate better survival, but predispose to tumorigenesis. Proc Natl Acad Sci USA 112: E6349-E6358, 2015.

27. Pavletich NP, Chambers KA and Pabo CO: The DNA-binding domain of p53 contains the four conserved regions and the major mutation hot spots. Genes Dev 7: 2556-2564, 1993.
28. Dittmer D, Pati S, Zambetti G, Chu S, Teresky AK, Moore M, Finlay $\mathrm{C}$ and Levine AJ: Gain of function mutations in p53. Nat Genet 4: 42-46, 1993.

29. Edge SB and Compton CC: The American Joint Committee on Cancer: The 7th edition of the AJCC cancer staging manual and the future of TNM. Ann Surg Oncol 17: 1471-1474, 2010.

30. Mao X, Zhang Z, Zheng X, Xie F, Duan F, Jiang L, Chuai S, Han-Zhang H,Han B and Sun J: Capture-based targeted ultradeep sequencing in paired tissue and plasma samples demonstrates differential subclonal ctDNA-releasing capability in advanced lung cancer. J Thorac Oncol 12: 663-672, 2017.

31. Li H and Durbin R: Fast and accurate short read alignment with Burrows-Wheeler transform. Bioinformatics 25: 1754-1760, 2009.

32. McKenna A, Hanna M, Banks E, Sivachenko A, Cibulskis K, Kernytsky A, Garimella K, Altshuler D, Gabriel S, Daly M and DePristo MA: The genome analysis toolkit: A MapReduce framework for analyzing next-generation DNA sequencing data. Genome Res 20: 1297-1303, 2010.

33. Van der Auwera GA, Carneiro MO, Hartl C, Poplin R, Del Angel G, Levy-Moonshine A, Jordan T, Shakir K, Roazen D, Thibault J, et al: From FastQ data to high confidence variant calls: The Genome analysis toolkit best practices pipeline. Curr Protoc Bioinformatics 43: 11.10.1-33, 2013.

34. Koboldt DC, Zhang Q, Larson DE, Shen D, McLellan MD, Lin L, Miller CA, Mardis ER, Ding L and Wilson RK: VarScan 2: Somatic mutation and copy number alteration discovery in cancer by exome sequencing. Genome Res 22: $568-576,2012$

35. 1000 Genomes Project Consortium, Auton A, Brooks LD, Durbin RM, Garrison EP, Kang HM, Korbel JO, Marchini JL, McCarthy S, McVean GA and Abecasis GR: A global reference for human genetic variation. Nature 526: 68-74, 2015.

36. Sherry ST, Ward MH, Kholodov M, Baker J, Phan L, Smigielski EM and Sirotkin K: dbSNP: The NCBI database of genetic variation. Nucleic Acids Res 29: 308-311, 2001.

37. Wang K, Li M and Hakonarson H: ANNOVAR: Functional annotation of genetic variants from high-throughput sequencing data. Nucleic Acids Res 38: e164, 2010.

38. Cingolani P, Platts A, Wang le L, Coon M, Nguyen T, Wang L, Land SJ, Lu X and Ruden DM: A program for annotating and predicting the effects of single nucleotide polymorphisms, SnpEff: SNPs in the genome of Drosophila melanogaster strain w1118; iso-2; iso-3. Fly (Austin) 6: 80-92, 2012.

39. Newman AM, Bratman SV, Stehr H, Lee LJ, Liu CL, Diehn M and Alizadeh AA: FACTERA: A practical method for the discovery of genomic rearrangements at breakpoint resolution. Bioinformatics 30: 3390-3393, 2014

40. RStudio Team: RStudio: Integrated Development for R. RStudio, Inc., Boston, MA, 2015. http://www.rstudio.com/.

41. Awad MM and Shaw AT: ALK inhibitors in non-small cell lung cancer: Crizotinib and beyond. Clin Adv Hematol Oncol 12: 429-439, 2014.

42. Karachaliou N, Sosa AE and Rosell R: Unraveling the genomic complexity of small cell lung cancer. Transl Lung Cancer Res 5: 363-366, 2016.

43. Remon J, Steuer CE, Ramalingam SS and Felip E: Osimertinib and other third-generation EGFR TKI in EGFR-mutant NSCLC patients. Ann Oncol 29 (Suppl 1): i20-i27, 2018.

44. Huang S, Benavente S, Armstrong EA, Li C, Wheeler DL and Harari PM: p53 modulates acquired resistance to EGFR inhibitors and radiation. Cancer Res 71: 7071-7079, 2011.

45. VanderLaan PA, Rangachari D, Mockus SM, Spotlow V, Reddi HV, Malcolm J, Huberman MS, Joseph LJ, Kobayashi SS and Costa DB: Mutations in TP53, PIK3CA, PTEN and other genes in EGFR mutated lung cancers: Correlation with clinical outcomes. Lung Cancer 106: 17-21, 2017.

46. Iwama E, Sakai K, Azuma K, Harada D, Nosaki K, Hotta K, Nishio M, Kurata T, Fukuhara T, Akamatsu H, et al: Exploration of resistance mechanisms for epidermal growth factor receptor-tyrosine kinase inhibitors based on plasma analysis by digital polymerase chain reaction and next-generation sequencing. Cancer Sci 109: 3921-3933, 2018.

47. Blandino G and Di Agostino S: New therapeutic strategies to treat human cancers expressing mutant p53 proteins. J Exp Clin Cancer Res 37: 30, 2018.

48. Kosaka T, Yatabe Y, Onozato R, Kuwano H and Mitsudomi T: Prognostic implication of EGFR, KRAS, and TP53 gene mutations in a large cohort of Japanese patients with surgically treated lung adenocarcinoma. J Thorac Oncol 4: 22-29, 2009. 
49. Trbusek M, Smardova J, Malcikova J, Sebejova L, Dobes P, Svitakova M, Vranova V, Mraz M, Francova HS, Doubek M, et al: Missense mutations located in structural p53 DNA-binding motifs are associated with extremely poor survival in chronic lymphocytic leukemia. J Clin Oncol 29: 2703-2708, 2011.

50. Szymanowska A, Jassem E, Dziadziuszko R, Skrzypski M, Kobierska-Gulida G, Holm K, Borg A, Rzyman W, Limon J and Jassem J: Analysis of prognostic value of TP53 gene mutations in non-small cell lung cancer. Pneumonol Alergol Pol 73: 264-269, 2005 (In Polish).

51. Ahrendt SA, Hu Y, Buta M, McDermott MP, Benoit N, Yang SC, Wu L and Sidransky D: p53 mutations and survival in stage I non-small-cell lung cancer: Results of a prospective study. J Nat Cancer Inst 95: 961-970, 2003

52. Huang C, Taki T, Adachi M, Konishi T, Higashiyama M and Miyake M: Mutations in exon 7 and 8 of p53 as poor prognostic factors in patients with non-small cell lung cancer. Oncogene 16: 2469-2477, 1998.

53. Skaug V, Ryberg D, Kure EH, Arab MO, Stangeland L, Myking AO and Haugen A: p53 mutations in defined structural and functiona domains are related to poor clinical outcome in non-small cell lung cancer patients. Clin Cancer Res 6: 1031-1037, 2000.

54. Lim EH, Zhang SL, Li JL, Yap WS, Howe TC, Tan BP, Lee YS, Wong D, Khoo KL, Seto KY, et al: Using whole genome amplification (WGA) of low-volume biopsies to assess the prognostic role of EGFR, KRAS, p53, and CMET mutations in advanced-stage non-small cell lung cancer (NSCLC). J Thorac Oncol 4: 12-21, 2009
55. Vikhanskaya F, Lee MK, Mazzoletti M, Broggini $M$ and Sabapathy K: Cancer-derived p53 mutants suppress p53-target gene expression-potential mechanism for gain of function of mutant p53. Nucleic Acids Res 35: 2093-2104, 2007.

56. Kim MP, Zhang Y and Lozano G: Mutant p53: Multiple mechanisms define biologic activity in cancer. Front Oncol 5: 249, 2015.

57. Gu J, Zhou Y, Huang L, Ou W, Wu J, Li S, Xu J, Feng J and Liu B: TP53 mutation is associated with a poor clinical outcome for non-small cell lung cancer: Evidence from a meta-analysis. Mol Clin Oncol 5: 705-713, 2016.

58. Murakami I, Hiyama K, Ishioka S, Yamakido M, Kasagi F and Yokosaki Y: p53 gene mutations are associated with shortened survival in patients with advanced non-small cell lung cancer: An analysis of medically managed patients. Clin Cancer Res 6: 526-530, 2000

This work is licensed under a Creative Commons Attribution-NonCommercial-NoDerivatives 4.0 International (CC BY-NC-ND 4.0) License. 